\title{
Back pain outcomes after minimally invasive anterior lumbar interbody fusion: a systematic review
}

\author{
Alvin Y. Chan, MD, ${ }^{1}$ Brian V. Lien, MS, ${ }^{1}$ Elliot H. Choi, MS, ${ }^{1}$ Andrew K. Chan, MD, ${ }^{2}$ \\ George Hanna, MD, ${ }^{1}$ Alexander M. Lopez, MD, MS, ${ }^{1}$ Nolan J. Brown, BS, ${ }^{1}$ Sandra Gattas, BS, ${ }^{1}$ \\ Lydia Kirillova, BS, ${ }^{1}$ David Horton, BS, ${ }^{1}$ Gianna Fote, BS, ${ }^{1}$ Brian Hanst, MS, ${ }^{1}$ Ryan Perry, DO, ${ }^{3}$ \\ Yu-Po Lee, MD, ${ }^{3}$ Kiarash Golshani, MD, ${ }^{1}$ Frank P. K. Hsu, MD, PhD, ${ }^{1}$ and Michael Y. Oh, MD ${ }^{1}$
}

Departments of ${ }^{1}$ Neurological Surgery and ${ }^{3}$ Orthopedic Surgery, University of California, Irvine; and ${ }^{2}$ Department of Neurological Surgery, University of California, San Francisco, California

OBJECTIVE Minimally invasive anterior lumbar interbody fusion surgery (MIS ALIF) is a technique that restores disc height and lumbar lordosis through a smaller exposure and less soft-tissue trauma compared to open approaches. The mini-open and laparoscopic assistance techniques are two main forms of MIS ALIF. The authors conducted a systematic review that sought to critically summarize the literature on back pain following MIS ALIF.

METHODS In March 2020, the authors searched the PubMed, Web of Science, and Cochrane Library databases for studies describing back pain visual analog scale (VAS) outcomes after MIS ALIF. The following exclusion criteria were applied to studies evaluated in full text: 1) the study included fewer than 20 patients, 2) the mean follow-up duration was shorter than 12 months, 3) the study did not report back pain VAS score as an outcome measure, and 4) MIS ALIF was not studied specifically. The methodology for the included studies were evaluated for potential biases and assigned a level of evidence.

RESULTS There were a total of 552 patients included from 13 studies. The most common biases were selection and interviewer bias. The majority of studies were retrospective. The mean sample size was 42.3 patients. The mean follow-up duration was approximately 41.8 months. The mean postoperative VAS reduction was 5.1 points. The mean VAS reduction for standalone grafts was 5.9 points, and 5.0 points for those augmented with posterior fixation. The most common complications included bladder or urinary dysfunction, infection, and hardware-related complications.

CONCLUSIONS This was a systematic review of back pain outcomes following MIS ALIF. Back pain VAS score was reduced postoperatively across all studies. The complication rates were low overall. MIS ALIF is safe and effective at reducing back pain in appropriate patient populations.

https://thejns.org/doi/abs/10.3171/2020.6.FOCUS20385

KEYWORDS laparoscopic; mini-open; visual analog scale; anterior lumbar interbody fusion; minimally invasive surgery

A NTERIOR lumbar interbody fusion (ALIF) is effective for managing degenerative or traumatic instability by fusing the spine via an anterior approach. ALIF allows restoration of both anterior disc height and lumbar lordosis, especially compared to other approaches. ${ }^{1,2}$ A retrospective study of 57 total patients comparing ALIF and transforaminal lumbar interbody fusion concluded that ALIF was superior for restoring foraminal height, the disc angle, and physiological lumbar lordosis. ${ }^{3}$ ALIF eliminates the need to dissect paraspinal muscles from the vertebrae associated with lateral approaches, thus decreasing the trauma and maintaining the vascular sup- ply to these muscles. ${ }^{4}$ Multilevel ALIF is likely also better for deformity correction and restoration of lumbar lordosis than larger posterior-based osteotomies. ${ }^{5}$ There are complications associated with opening the abdomen during ALIF, which include vascular injury, sexual dysfunction, pancreatitis, bowel injury, and ileus. ${ }^{6}$ Therefore, minimizing exposure is preferred to limit complications.

Minimally invasive spine surgery (MISS) has become an attractive alternative to open approaches, allowing for decreased infection rates and shorter recovery periods.? MISS has reduced soft-tissue damage compared to open surgery, ${ }^{8}$ and with reliance on fluoroscopy or laparosco-

ABBREVIATIONS ALIF = anterior lumbar interbody fusion; DDD = degenerative disc disease; MIS = minimally invasive surgery; MISS = minimally invasive spine surgery; PRISMA = Preferred Reporting Items for Systematic Reviews and Meta-Analyses; VAS = visual analog scale.

SUBMITTED May 4, 2020. ACCEPTED June 9, 2020.

INCLUDE WHEN CITING DOI: 10.3171/2020.6.FOCUS20385. 


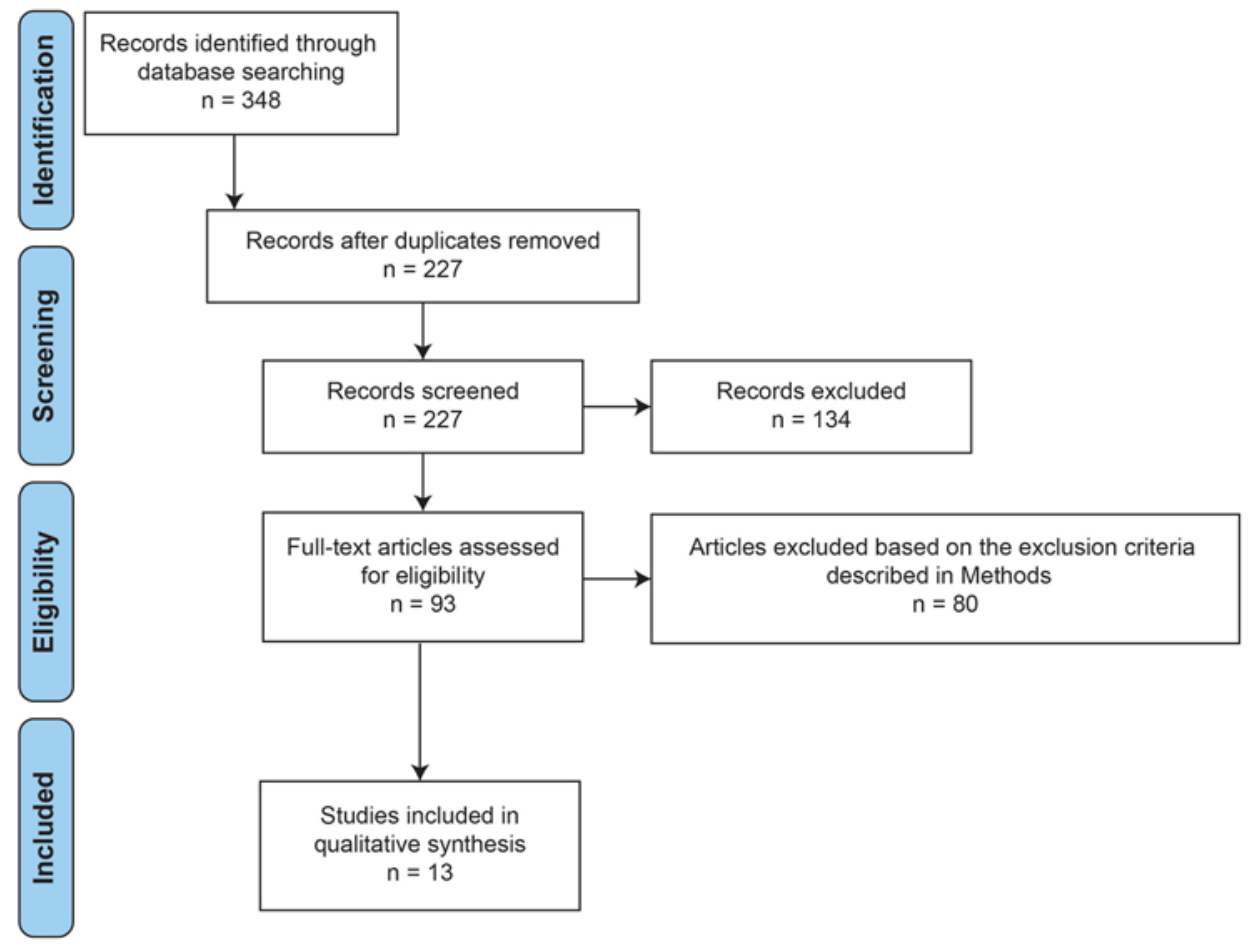

FIG. 1. PRISMA diagram. Process of exclusion and inclusion of studies.

py allows adequate visibility through smaller exposures.? ALIF can be performed minimally invasively, and studies describing the mini-open, video-assisted, or image-guided ALIF have shown favorable outcomes. ${ }^{9-11}$ A study of 98 patients who underwent ALIF via either a mini-open exposure or laparoscopy concluded that one technique did not have a definitive benefit over the other. ${ }^{12}$ Furthermore, a prospective study of 54 patients that compared laparoscopic minimally invasive surgery (MIS) with an open approach showed there was no difference in outcomes or fusion rates. ${ }^{13}$

Despite this, there have been no systematic reviews conducted on MIS ALIF. To address this gap, we performed a review of available demographic, clinical information, and pre- and postoperative measures with attention to back pain using the visual analog scale (VAS). Our study aimed to provide a concise representation of the current literature of MIS ALIF while identifying advantages and limitations.

\section{Methods}

\section{Literature Search}

In March 2020 we searched the PubMed, Web of Science, and Cochrane databases for articles containing clinical VAS outcomes after MIS ALIF that were published in the last 20 years. We used the following search terms ("minimally invasive" or "MIS" or "mini-open" or "mini open" or "laparoscopic" or "mini-ALIF" or "mini ALIF") AND ("anterior lumbar interbody fusion" OR "anterior lumbar fusion" OR "anterior lumbar surgery" OR "ALIF"). Two authors (A.Y.C. and B.V.L.) independently reviewed the articles. Discrepancies were resolved by dis- cussion and consensus. Data extraction was performed by B.V.L. and reassessed by A.Y.C. and E.H.C.

\section{Study Criteria and Data Collection}

The search returned 154 results from PubMed, 187 from Web of Science, and 7 from the Cochrane Library, totaling 227 unique citations after exclusion of duplicates. The following inclusion criteria were applied: 1) primary clinical study reporting VAS outcomes after MIS ALIF, 2) English language only; and 3) publication date within the last two decades. If the study in the title and abstract did not specify minimally invasive, the full text was reviewed (Fig. 1).

Overall, 93 potential studies met our inclusion criteria and were reviewed in full text. The following exclusion criteria were applied: 1) data from fewer than 20 patients, 2) the mean follow-up duration for the study was less than 12 months, 3) back pain VAS score was not included as an outcome measure, and 4) the article not investigating MIS ALIF specifically. ALIF included antepsoas approaches, and strictly lateral surgeries were excluded. Ultimately, 13 studies met the inclusion and exclusion criteria. This literature review was designed and performed using Preferred Reporting Items for Systematic Reviews and Meta-Analyses (PRISMA) guidelines. ${ }^{14}$ Data from each study were collected for back pain VAS score, complications, and whether the patient had a standalone interbody fixation, as well as an additional posterior fixation.

We assessed the study methodology for each of the 13 selected studies for potential biases and assigned a level of evidence as previously described.$^{14}$ Briefly, interviewer bias was defined as a systematic difference between how information was solicited, recorded, or interpreted (e.g., no 
blinding). Recall bias was defined as bias due to outcomes of treatment affecting the patient's memory for previous events. Selection bias was defined as bias due to patient loss to follow-up or if the exposure and outcome occurred before patient selection. Response bias was defined as bias occurring with self-report and surveys.

\section{Results}

The initial search resulted in 348 articles. After the screening and assessment of full-text articles, 13 studies fulfilled the inclusion criteria. ${ }^{9,10,13,15-24}$ There were 552 patients included from these studies (Table 1). The level of evidence ranged from II to IV. The most common biases included selection bias $(92.3 \%)$ and interviewer bias (84.6\%). Approximately 38.5\% (5/13) of studies were prospective and $69.2 \%(9 / 13)$ were retrospective. The patient demographics, study design, diagnosis, followup duration, location of surgeries, and surgical approach are summarized in Table 2. The mean collective sample size was 42.5 (range 20-142). The collective ratio of male to female study participants was 1 to 1.5 . The mean collective follow-up duration was 41.8 months (range 3-120 months). Supplemental posterior screw fixation was performed in $43.5 \%(240 / 552)$ of patients, whereas ALIF was performed alone in $56.5 \%(312 / 552)$ of patients. The most common operated levels were L4-5 and L5-S1, with 9 studies reported for each.

The VAS score for back pain was collected preoperatively and postoperatively (Table 3). Two different scales for the VAS were used. Eleven studies used a scale ranging from $0-10,{ }^{9,10,13,15,17-23}$ whereas 2 studies used a scale ranging from $0-100 .{ }^{16,24}$ The scale ranging from $0-100$ was normalized to the scale ranging from $0-10$ in this study. The mean postoperative VAS score reduction was 5.1 points. The mean VAS score reduction for standalone grafts was 5.9 points, and 5.0 points for posterior fixation.

The rate of complication and complication types are summarized in Table 4. The overall complication rate for standalone fixation $(9.9 \%, 10 / 101)$ was lower than with posterior fixation $(20.2 \%, 41 / 203)$. Complications that were relatively common included bladder or urinary dysfunction $(2.5 \%, 14 / 552)$, infection $(2.4 \%, 13 / 552)$, hardware-related complications $(2.2 \%, 12 / 552)$, fracture $(1.3 \%$, $7 / 552)$, vascular injury $(1.1 \%, 6 / 552)$, wound-related complications $(1.1 \%, 6 / 552)$, and neurological complications $(1.1 \%, 6 / 552)$. Rarer complications included gastrointestinal-related complications $(0.9 \%, 5 / 552)$, deep vein thrombosis $(0.7 \%, 4 / 552)$, and retrograde ejaculation $(0.4 \%$, 2/552). Hardware-related complications include malpositioned cages or pedicle screws causing symptoms. Woundrelated complications included wound dehiscence, wound hematoma, or incision site pain. Neurological complications include L5 palsy, pain due to foraminal stenosis, and numbness. Gastrointestinal complications included bowel injury, paralytic ileus, or common bile duct lithiasis.

\section{Discussion}

This systematic review assesses the change in back pain VAS scores and the complications after MIS ALIF. We reviewed 552 cases from 13 studies for qualitative and quantitative analysis. Of the 13 studies, 11 were level IV
TABLE 1. Studies with sample size, level of evidence, and potential biases

\begin{tabular}{|c|c|c|c|}
\hline Authors \& Year & $\begin{array}{l}\text { Sample } \\
\text { Size }\end{array}$ & $\begin{array}{l}\text { Evidence } \\
\text { Level }\end{array}$ & Potential Biases \\
\hline Aunoble et al., $2006^{10}$ & 20 & IV & Interviewer, selection \\
\hline Chung et al., $2003^{13}$ & 44 & II & Interviewer, selection \\
\hline Farah et al., $2018^{15}$ & 43 & IV & Interviewer, selection \\
\hline $\begin{array}{l}\text { Flouzat-Lachaniette et al., } \\
\qquad 2015^{16}\end{array}$ & 47 & IV & Selection, responder \\
\hline Hironaka et al., $2013^{17}$ & 142 & IV & Interviewer, selection \\
\hline Hosseini et al., $2017^{18}$ & 39 & IV & Interviewer, selection \\
\hline Kim et al., $2010^{19}$ & 63 & IV & Interviewer, selection \\
\hline Kleeman et al., $2001^{20}$ & 22 & II & Interviewer, selection \\
\hline Lin et al., $2015^{21}$ & 22 & IV & Interviewer, selection \\
\hline Mamuti et al., $2016^{9}$ & 35 & IV & Interviewer, selection \\
\hline Park et al., $2009^{22}$ & 29 & IV & Interviewer, selection \\
\hline Shim et al., $2005^{23}$ & 20 & IV & Selection, responder \\
\hline Tobler \& Ferrara, $2011^{24}$ & 26 & IV & Interviewer \\
\hline
\end{tabular}

evidence, and 2 studies were level II evidence. In these studies, the MIS ALIF indications including degenerative disc diseases (DDDs), foraminal stenosis, spinal deformity, and failed posterior fusion were similar to the open ALIF indications. Associated symptoms include neurogenic claudication, radiculopathy, and leg or low-back pain..$^{25-27}$ All studies reported a decrease in overall mean back pain VAS scores postoperatively. Although there was a wide range of complications after MIS ALIF, the complication rates were low overall. The most prevalent complications were bladder or urinary dysfunction $(2.5 \%, 14 / 552)$, infection $(2.4 \%, 13 / 552)$, and hardware-related complications $(2.2 \%, 12 / 552)$.

\section{Mini-Open and Laparoscopic}

MIS ALIF can be performed via a mini-open exposure versus laparoscopic assistance. The mini-open approach is a variation on the original open approach that utilizes muscle-splitting techniques to minimize soft-tissue trauma. ${ }^{28}$ Mini-open ALIF has been shown to be effective. A retrospective study of 684 patients concluded that the miniopen approach could be performed quickly with low rates of complications..$^{29}$ A laparoscopic approach was also developed after improvements in interbody fusion cage technologies. Regan et al. described a study of 240 total patients who underwent either laparoscopic or traditional-approach ALIF and found that complication rates were similar between groups, but the laparoscopic group had shorter hospital length of stay and reduced intraoperative blood loss. ${ }^{30}$ However, the authors conceded that the approach was technically difficult and that $10 \%$ of cases were converted to open approaches. In direct comparisons between miniopen and laparoscopic approaches, there appear to be no substantial differences. A prospective study of 50 consecutive total patients comparing the two approaches found there was no difference in surgical duration, blood loss, or length of stay, although the complication rate was higher among the laparoscopic group. ${ }^{31}$ There do not appear to be 


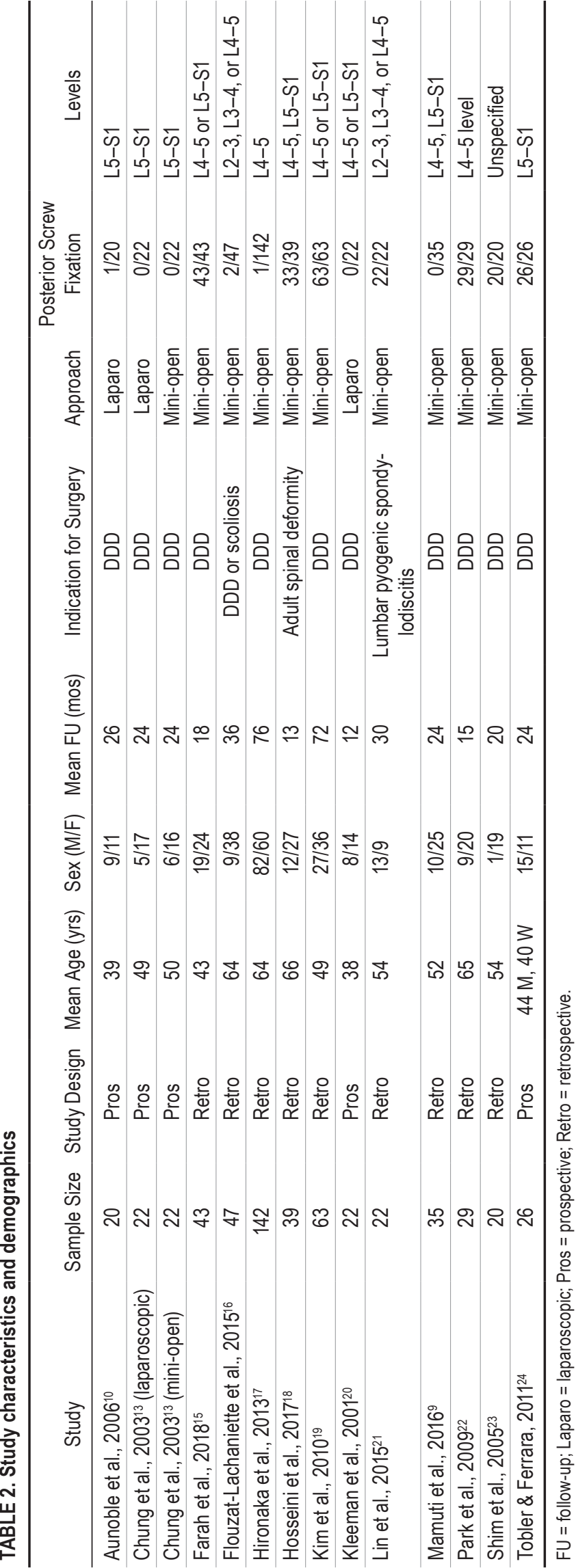

TABLE 3. Summary of reduction in postoperative back pain VAS score

\begin{tabular}{|c|c|c|c|c|}
\hline \multirow[b]{2}{*}{ Authors \& Year } & \multirow{2}{*}{$\begin{array}{c}\text { Sample } \\
\text { Size }\end{array}$} & \multicolumn{3}{|c|}{ VAS Score } \\
\hline & & Preop & Postop & Change \\
\hline Aunoble et al., $2006^{10}$ & 20 & 6.5 & 2.7 & 3.8 \\
\hline Chung et al., $2003^{13}$ & 22 & 9.1 & 4.0 & 5.1 \\
\hline Chung et al., $2003^{13}$ & 22 & 9.4 & 3.7 & 5.7 \\
\hline Farah et al., $2018^{15}$ & 43 & 7 & 2 & 5 \\
\hline Flouzat-Lachaniette et al., $2015^{16}$ & 47 & 6.3 & 3.1 & 3.2 \\
\hline Hironaka et al., $2013^{17}$ & 142 & 8.7 & 3.0 & 5.7 \\
\hline Hosseini et al., $2017^{18}$ & 39 & 6.8 & 2.1 & 4.7 \\
\hline Kim et al., $2010^{19}$ & 63 & 6.2 & 1.7 & 4.5 \\
\hline Kleeman et al., $2001^{20}$ & 22 & 7.7 & 1.9 & 5.8 \\
\hline Lin et al., $2015^{21}$ & 22 & 7.5 & 0.6 & 6.9 \\
\hline Mamuti et al., $2016^{9}$ & 35 & 7.9 & 1.4 & 6.5 \\
\hline Park et al., $2009^{22}$ & 29 & 6.6 & 1.5 & 5.1 \\
\hline Shim et al., $2005^{23}$ & 20 & NA & NA & 7.3 \\
\hline Tobler \& Ferrara, $2011^{24}$ & 26 & 6.7 & 3.7 & 3.0 \\
\hline
\end{tabular}

$\mathrm{NA}=$ not available.

All VAS data are provided as means.

any clear advantages for either technique. ${ }^{12,30,31}$ Our review evaluated studies utilizing both techniques. The VAS score for back pain was significantly reduced postoperatively in all studies. The laparoscopic approach is more technically difficult. One consideration with any minimally invasive approach is that vascular injury can be difficult to control through small exposures.

\section{VAS Outcomes}

MIS ALIF has been shown to reduce back pain in appropriately selected patients with high-grade spondylolisthesis, DDD, central canal stenosis, and spinal deformity. ${ }^{27,32,33}$ All studies showed a significant reduction in VAS scores postoperatively (Table 2). For example, Hironaka et al. retrospectively reviewed 142 patients undergoing L4-5 mini-open ALIF for degenerative disease and found that VAS scores for back pain were significantly reduced postoperatively. ${ }^{17}$ The reason is likely that ALIF allows for anterior longitudinal ligament release and larger anterior interbody placement, restoring physiological lumbar lordosis. ${ }^{27}$ MIS ALIF may prevent damage to paraspinal muscles and ligaments because anterior interbody placement may circumvent the requirement for posterior decompression in comparison to other approaches. However, there have been variable rates of fusion in the literature, which may be why standalone ALIF is less common and often augmented with posterior fixation. ${ }^{34}$ MIS ALIF shows pain reduction comparable to open techniques. ${ }^{12}$

\section{Complications}

A summary of complications for each study is listed in Table 4. Complications from ALIF are rare but have the potential to be devastating. The risk is augmented when the exposure is smaller, as it is with MIS approaches. Although the rates were low, the various complications reported in 
TABLE 4. Complication reported

\begin{tabular}{|c|c|c|}
\hline Authors \& Year & $\begin{array}{l}\text { Complication } \\
\text { Rate }\end{array}$ & Complications \\
\hline Aunoble et al., $2006^{10}$ & NA & $1 / 20$ vascular complication, $1 / 20$ donor-site infection, $1 / 20$ superficial wound dehiscence \\
\hline Chung et al., $2003^{13}$ (laparoscopic) & $13.64 \%$ & $1 / 22$ cage malposition, $1 / 22$ retrograde ejaculation, $1 / 22$ bladder dysfunction \\
\hline Chung et al., $2003^{13}$ (mini-open) & $9.09 \%$ & $1 / 22$ deep vein thrombosis, $1 / 22$ bladder dysfunction \\
\hline Farah et al., $2018^{15}$ & $4.60 \%$ & 1/43 superficial wound infection, $1 / 43$ urinary infection \\
\hline Flouzat-Lachaniette et al., $2015^{16}$ & $12.70 \%$ & $\begin{array}{l}\text { 1/47 iliac vein laceration, } 1 / 47 \text { ureteral injury, } 1 / 47 \text { L3 corporeal fracture, } 2 / 47 \text { endplate fractures, } \\
1 / 47 \text { L5 palsy, } 1 / 47 \text { acute coronary syndrome, } 1 / 47 \text { cardiac arrest, } 1 / 47 \text { acute cardiac, } 1 / 47 \text { com- } \\
\text { mon bile duct lithiasis, } 6 / 47 \text { acute urinary retention, } 4 / 47 \text { urinary tract infection, 1/47 paralytic } \\
\text { ileus }\end{array}$ \\
\hline Hironaka et al., $2013^{17}$ & $2.82 \%$ & $\begin{array}{l}\text { 1/142 wound infection, } 1 / 142 \text { liquorrhea due to a dural tear injury, } 1 / 142 \text { vertebral body fractures } \\
\text { needing a posterior pedicle screw fixation, } 1 / 142 \text { misplaced cage that required revision }\end{array}$ \\
\hline Hosseini et al., $2017^{18}$ & $35.90 \%$ & $\begin{array}{l}\text { 2/39 urinary tract infection, } 1 / 39 \text { bilateral leg swelling, } 1 / 39 \text { wound dehiscence, } 1 / 39 \text { adult spinal } \\
\text { deformity, } 6 / 39 \text { proximal junctional kyphosis, } 1 / 39 \text { deep vein thrombosis, } 1 / 39 \text { decreased postop } \\
\text { L4-S1 sensation; } 2 / 39 \text { screw loosening, } 1 / 39 \text { hematoma, } 1 / 39 \text { vertebral body fracture, } 1 / 39 \\
\text { encephalopathy, } 2 / 39 \text { ileus, } 1 / 39 \text { endplate fracture, } 1 / 39 \text { renal failure, } 1 / 39 \text { acute transaminitis, } \\
\text { 1/39 respiratory tract infection, } 2 / 39 \text { deep surgical site infection }\end{array}$ \\
\hline Kim et al., $2010^{19}$ & $8.20 \%$ & $3 / 73$ left iliac vein injuries, $2 / 73$ wound hematomas, $1 / 73$ deep vein thrombosis \\
\hline Kleeman et al., $2001^{20}$ & $9.00 \%$ & $1 / 22$ bowel injury, $1 / 22$ vascular injury \\
\hline Lin et al., $2015^{21}$ & $45.45 \%$ & $5 / 22$ urinary retention, $3 / 22$ constipation, $2 / 22$ numbness in thigh \\
\hline Mamuti et al., $2016^{9}$ & $5.71 \%$ & $1 / 35$ deep vein thrombosis, $1 / 35$ retrograde ejaculation and unilateral vasodilation of lower limb \\
\hline Park et al., 200922 & $0 \%$ & None \\
\hline Shim et al., $2005^{23}$ & $5.00 \%$ & $1 / 20$ compressed L5 root and radicular pain \\
\hline Tobler \& Ferrara, $2011^{24}$ & NA & $\begin{array}{l}\text { 7/26 pedicle screw removal for pain, } 2 / 26 \text { foraminal stenosis radiculopathy, } 1 / 26 \text { incisional pain, } \\
1 / 26 \text { nerve impingement from pedicle screw }\end{array}$ \\
\hline
\end{tabular}

our studies were wide and included vascular injury, retrograde ejaculation, bladder dysfunction, wound complications, infection, proximal junctional kyphosis, screw loosening, ileus, and nerve impingement. Complications varied between studies. For example, Flouzat-Lachaniette et al. reported urinary symptoms as being most common, while Hosseini et al. reported more structural complications (e.g., proximal junction kyphosis, screw loosening, etc.). ${ }^{16,18}$ There were 4 studies that reported vascular injury, and the rates were low overall (1.1\%). MIS approaches are often converted to open approaches to control hemorrhaging in these cases. Most vascular injuries associated with ALIF occur around L4-5. The vascular complication rates are comparable among MIS and open approaches, although evidence in the literature has been limited and of low quality. ${ }^{35}$ Further higher quality research is required to evaluate the exact difference in complication risk between MIS and open approaches.

\section{Study Limitations}

There are limitations to our study that must be considered. First, the majority of studies were retrospective and of a low level of evidence, as summarized in Table 1. Although retrospective studies are typical of spine literature, they are vulnerable to recall or response biases. Second, the sample size was small for most of the studies included (e.g., fewer than 100 subjects), which confers vulnerability to potential biases such as publication bias. Third, there was heterogeneity among the studies in terms of indications for MIS ALIF (e.g., disc degeneration, spondylo- listhesis, disc herniation, scoliosis, pseudoarthrosis, etc.). Fourth, there was heterogeneity in terms of technique (e.g., laparoscopic vs mini-open) that also made standardization of results challenging. These limitations should be considered when drawing conclusions from our study.

\section{Conclusions}

We presented a systematic review of back pain outcomes following MIS ALIF, which included mini-open and laparoscopic techniques. There was a reliable reduction in back pain postoperatively across all included studies. The complication rates were low, including vascular injury. Future studies should focus on a higher level of evidence and larger sample sizes.

\section{References}

1. Teng I, Han J, Phan K, Mobbs R. A meta-analysis comparing ALIF, PLIF, TLIF and LLIF. J Clin Neurosci. 2017;44:11-17.

2. Choy WJ, Abi-Hanna D, Cassar LP, et al. History of integral fixation for anterior lumbar interbody fusion (ALIF): the Hartshill horseshoe. World Neurosurg. 2019;129:394-400.

3. Hsieh PC, Koski TR, O’Shaughnessy BA, et al. Anterior lumbar interbody fusion in comparison with transforaminal lumbar interbody fusion: implications for the restoration of foraminal height, local disc angle, lumbar lordosis, and sagittal balance. J Neurosurg Spine. 2007;7(4):379-386.

4. Garcia RM, Choy W, DiDomenico JD, et al. Thirty-day readmission rate and risk factors for patients undergoing single level elective anterior lumbar interbody fusion (ALIF). $J$ Clin Neurosci. 2016;32:104-108.

5. Chan AK, Mummaneni PV, Shaffrey CI. Approach selection: 
multiple anterior lumbar interbody fusion to recreate lumbar lordosis versus pedicle subtraction osteotomy: when, why, how? Neurosurg Clin N Am. 2018;29(3):341-354.

6. Rajaraman V, Vingan R, Roth P, et al. Visceral and vascular complications resulting from anterior lumbar interbody fusion. J Neurosurg. 1999;91(1)(suppl):60-64.

7. Banczerowski P, Czigléczki G, Papp Z, et al. Minimally invasive spine surgery: systematic review. Neurosurg Rev. 2015; 38(1):11-26.

8. Narain AS, Hijji FY, Duhancioglu G, et al. Patient perceptions of minimally invasive versus open spine surgery. Clin Spine Surg. 2018;31(3):E184-E192.

9. Mamuti M, Fan S, Liu J, et al. Mini-open anterior lumbar interbody fusion for recurrent lumbar disc herniation following posterior instrumentation. Spine (Phila Pa 1976). 2016;41(18): E1104-E1114.

10. Aunoble S, Hoste D, Donkersloot P, et al. Video-assisted ALIF with cage and anterior plate fixation for L5-S1 spondylolisthesis. J Spinal Disord Tech. 2006;19(7):471-476.

11. Xiao R, Miller JA, Sabharwal NC, et al. Clinical outcomes following spinal fusion using an intraoperative computed tomographic 3D imaging system. J Neurosurg Spine. 2017; 26(5):628-637.

12. Kaiser MG, Haid RW Jr, Subach BR, et al. Comparison of the mini-open versus laparoscopic approach for anterior lumbar interbody fusion: a retrospective review. Neurosurgery. 2002; 51(1):97-105.

13. Chung SK, Lee SH, Lim SR, et al. Comparative study of laparoscopic L5-S1 fusion versus open mini-ALIF, with a minimum 2-year follow-up. Eur Spine J. 2003;12(6):613-617.

14. Shamseer L, Moher D, Clarke M, et al. Preferred reporting items for systematic review and meta-analysis protocols (PRISMA-P) 2015: elaboration and explanation. BMJ. 2015; 350:g7647.

15. Farah K, Graillon T, Rakotozanany P, et al. Circumferential minimally invasive approach for low-grade isthmic spondylolisthesis: a clinical and radiological study of 43 patients. Orthop Traumatol Surg Res. 2018;104(5):575-579.

16. Flouzat-Lachaniette $\mathrm{CH}$, Ratte L, Poignard A, et al. Minimally invasive anterior lumbar interbody fusion for adult degenerative scoliosis with 1 or 2 dislocated levels. J Neurosurg Spine. 2015;23(6):739-746.

17. Hironaka Y, Morimoto T, Motoyama Y, et al. Surgical management of minimally invasive anterior lumbar interbody fusion with stand-alone interbody cage for L4-5 degenerative disorders: clinical and radiographic findings. Neurol Med Chir (Tokyo). 2013;53(12):861-869.

18. Hosseini P, Mundis GM Jr, Eastlack RK, et al. Preliminary results of anterior lumbar interbody fusion, anterior column realignment for the treatment of sagittal malalignment. Neurosurg Focus. 2017;43(6):E6.

19. Kim JS, Choi WG, Lee SH. Minimally invasive anterior lumbar interbody fusion followed by percutaneous pedicle screw fixation for isthmic spondylolisthesis: minimum 5-year follow-up. Spine J. 2010;10(5):404-409.

20. Kleeman TJ, Ahn UM, Talbot-Kleeman A. Laparoscopic anterior lumbar interbody fusion with rhBMP-2: a prospective study of clinical and radiographic outcomes. Spine (Phila Pa 1976). 2001;26(24):2751-2756.

21. Lin Y, Li F, Chen W, et al. Single-level lumbar pyogenic spondylodiscitis treated with mini-open anterior debridement and fusion in combination with posterior percutaneous fixation via a modified anterior lumbar interbody fusion approach. J Neurosurg Spine. 2015;23(6):747-753.

22. Park SH, Park WM, Park CW, et al. Minimally invasive anterior lumbar interbody fusion followed by percutaneous translaminar facet screw fixation in elderly patients. J Neurosurg Spine. 2009;10(6):610-616.

23. Shim CS, Lee SH, Jung B, et al. Fluoroscopically assisted percutaneous translaminar facet screw fixation following an- terior lumbar interbody fusion: technical report. Spine (Phila Pa 1976). 2005;30(7):838-843.

24. Tobler WD, Ferrara LA. The presacral retroperitoneal approach for axial lumbar interbody fusion: a prospective study of clinical outcomes, complications and fusion rates at a follow-up of two years in 26 patients. J Bone Joint Surg Br. 2011;93(7):955-960.

25. Mobbs RJ, Phan K, Malham G, et al. Lumbar interbody fusion: techniques, indications and comparison of interbody fusion options including PLIF, TLIF, MI-TLIF, OLIF/ATP, LLIF and ALIF. J Spine Surg. 2015;1(1):2-18.

26. Rao PJ, Loganathan A, Yeung V, Mobbs RJ. Outcomes of anterior lumbar interbody fusion surgery based on indication: a prospective study. Neurosurgery. 2015;76(1):7-24.

27. Xu DS, Walker CT, Godzik J, et al. Minimally invasive anterior, lateral, and oblique lumbar interbody fusion: a literature review. Ann Transl Med. 2018;6(6):104.

28. Mayer HM. A new microsurgical technique for minimally invasive anterior lumbar interbody fusion. Spine (Phila Pa 1976). 1997;22(6):691-700.

29. Brau SA. Mini-open approach to the spine for anterior lumbar interbody fusion: description of the procedure, results and complications. Spine J. 2002;2(3):216-223.

30. Regan JJ, Yuan H, McAfee PC. Laparoscopic fusion of the lumbar spine: minimally invasive spine surgery. A prospective multicenter study evaluating open and laparoscopic lumbar fusion. Spine (Phila Pa 1976). 1999;24(4):402-411.

31. Zdeblick TA, David SM. A prospective comparison of surgical approach for anterior L4-L5 fusion: laparoscopic versus mini anterior lumbar interbody fusion. Spine (Phila Pa 1976). 2000;25(20):2682-2687.

32. Ahmadian A, Verma S, Mundis GM Jr, et al. Minimally invasive lateral retroperitoneal transpsoas interbody fusion for L4-5 spondylolisthesis: clinical outcomes. J Neurosurg Spine. 2013;19(3):314-320.

33. Benglis DM, Elhammady MS, Levi AD, Vanni S. Minimally invasive anterolateral approaches for the treatment of back pain and adult degenerative deformity. Neurosurgery. 2008; 63(3)(suppl):191-196.

34. Truumees E, Majid K, Brkaric M. Anterior lumbar interbody fusion in the treatment of mechanical low back pain. Semin Spine Surg. 2008;20(2):113-125.

35. Inamasu J, Guiot $\mathrm{BH}$. Vascular injury and complication in neurosurgical spine surgery. Acta Neurochir (Wien). 2006; 148(4):375-387.

\section{Disclosures}

Dr. Andrew K. Chan reports support of non-study-related clinical or research effort from Orthofix Medical, Inc.

\section{Author Contributions}

Conception and design: Oh, AY Chan. Acquisition of data: Oh, AY Chan, Lien, Choi, Brown, Gattas, Kirillova, Horton, Fote. Analysis and interpretation of data: Oh, AY Chan, Lien, Choi, AK Chan, Hanna, Lopez, Brown, Gattas, Kirillova, Horton, Fote. Drafting the article: Oh, AY Chan, Lien, Choi, AK Chan, Hanna, Lopez, Brown, Gattas. Critically revising the article: Oh, AY Chan, AK Chan, Hanna, Lopez, Brown, Perry, Lee, Golshani, Hsu. Reviewed submitted version of manuscript: Oh, AY Chan, Lien, Hanst, Perry, Lee, Golshani, Hsu. Statistical analysis: Oh, AY Chan, Choi. Administrative/technical/material support: Oh, AY Chan, Choi. Study supervision: Oh, Golshani, Hsu.

\section{Correspondence}

Michael Y. Oh: University of California, Irvine, CA. ohm2@ hs.uci.edu. 